TRABAJOS ORIGINALES

Rev Obstet Ginecol Venez. 2022; 82 (1): 5-20.

https://doi.org/10.51288/00820104

\title{
COVID-19 durante la gestación: resultados maternos y perinatales
}

\author{
(D) Mercedes Paola Castro Áñez, ${ }^{1}$ (D) Olga María Mora Carrero, ${ }^{2}$ (D) Teresa Narváez, ${ }^{3}$ \\ Mireya González Blanco. ${ }^{4}$
}

\begin{abstract}
RESUMEN
Objetivo: Evaluar los resultados maternos y perinatales asociados a la COVID-19 durante la gestación, en mujeres que acudieron al servicio de aislamiento del Hospital Central de San Cristóbal, en el periodo agosto 2020- julio 2021.

Métodos: Estudio retrospectivo o ex post facto, observacional, descriptivo, transversal, con diseño documental. Incluyó una muestra no probabilística de 30 pacientes que ingresaron con diagnóstico sospechado o confirmado de COVID-19. Se revisaron las historias clínicas para identificar la evolución materna y perinatal.

Resultados: La frecuencia de COVID-19 fue de 0,5 casos por cada 100 gestantes. Las 30 pacientes tenían diagnóstico confirmado. Hubo 16 casos leves (53,3\%), 5 moderados (16,7\%) y 9 graves $(30 \%)$. Los sintomas predominantes fueron tos y dificultad respiratoria (100\%), cefalea (96,7 \%) y fiebre (90\%). Hubo elevación de ferritina en $100 \%$ de los casos, dimero D en 33,3\% y LDH en $90 \%$. La evolución grave no se asoció a los factores de riesgo conocidos. Hubo complicaciones obstétricas en $90 \%$ de las pacientes, las más frecuentes fueron parto pretérmino (40\%) y oligohidramnios (36,7\%). Hubo 6 muertes maternas (20,0\%). La evolución de la enfermedad fue insatisfactoria en $46,7 \%$ de las pacientes, con $40 \%$ de ingreso a la unidad de cuidados intensivos y $30 \%$ de apoyo ventilatorio. La tasa de cesárea fue de $86,7 \%$. El 70 \% de los RN evolucionaron satisfactoriamente. Hubo 7 muertes perinatales $(23,3 \%)$. Conclusión: La COVID-19 se asocia a evolución materna y perinatal adversa.
\end{abstract}

Palabras clave: COVID-19, Embarazo, Resultado materno, Resultado perinatal.

\section{COVID-19 during pregnancy: maternal and perinatal outcomes} SUMMARY

Objective: To evaluate the maternal and perinatal outcomes associated with COVID-19 during pregnancy, in women who attended the isolation service of the Hospital Central de San Cristóbal, in the period August 2020-July 2021.

Methods: Retrospective or ex post facto, observational, descriptive, cross-sectional study with documentary design. It included a non-probabilistic sample of 30 patients admitted with a suspected or confirmed diagnosis of COVID-19. Medical records were reviewed to identify maternal and perinatal evolution.

Results: The frequency of COVID-19 was 0.5 cases per 100 pregnant women. All 30 patients had a confirmed diagnosis. There were 16 mild cases (53.3\%), 5 moderate $(16.7 \%)$ and 9 severe (30\%). The predominant symptoms were cough and shortness of breath (100\%), headache (96.7\%) and fever (90\%). There was an increase in ferritin in $100 \%$ of the cases, D-dimer in $33.3 \%$ and LDH in $90 \%$. Severe evolution was not associated with known risk factors. There were obstetric complications in $90 \%$ of the patients, the most frequent were preterm birth (40\%) and oligohydramnios (36.7\%). There were 6 maternal deaths (20.0\%). The evolution of the disease was unsatisfactory in $46.7 \%$ of the patients, with $40 \%$ of admission to the intensive care unit and $30 \%$ of ventilatory support. The caesarean section rate was $86.7 \% .70 \%$ of the RNs progressed satisfactorily. There were 7 perinatal deaths (23.3\%).

Conclusion: COVID-19 is associated with adverse maternal and perinatal evolution.

Keywords: COVID-19, Pregnancy, Maternal outcome, Perinatal outcome.

\begin{abstract}
${ }^{1}$ Médico Cirujano, especialista en Obstetricia y Ginecología. ${ }^{2}$ Médico Cirujano, especialista en Obstetricia y Ginecología, Profesora de la Facultad de Medicina de la Universidad de los Andes, Núcleo Táchira. ${ }^{3}$ Médico Cirujano, especialista en Obstetricia y Ginecología y en Medicina Materno Fetal. ${ }^{4}$ Médico Cirujano, especialista en Obstetricia y Ginecología, Miembro Titular de la Sociedad de Obstetricia y Ginecología de Venezuela. *Trabajo especial de grado presentado por la médico cirujano Mercedes Paola Castro Añez ante la Universidad de Los Andes para la obtención del grado de Especialista en Ginecología y Obstetricia. Correo de correspondencia: mercedescastrop@hotmail.com
\end{abstract}

Forma de citar este artículo: Castro Añez MP, Mora Carrero OM, Narváez T, González-Blanco M. COVID-19 durante la gestación: resultados maternos y perinatales. Rev Obstet Ginecol Venez. 2022; 82(1): 5-20. https://doi.org/10.51288/00820104

\section{INTRODUCCIÓN}

El virus del síndrome respiratorio agudo grave tipo-2 (SARS-CoV-2), causante de la COVID-19 (Coronavirus disease 19), se ubica taxonómicamente en la familia Coronaviridae $(1,2)$. 
El 31 de diciembre de 2019 se hizo el anuncio del primer caso de neumonía por un nuevo coronavirus, el SARS-CoV-2, en la ciudad de Wuhan, provincia de Hubei, en China; desde entonces, se inició la aparición de casos a nivel mundial, alcanzando tal magnitud que, para el 13 de marzo de 2020, la Organización Mundial de la Salud (OMS) la reconoció como pandemia (3 - 5).

Sin embargo, en el país hay pocos reportes de la enfermedad, asociada a la gestación, que evalúen la evolución materna y perinatal. En abril de 2020, el Colegio Americano de Obstetras y Ginecólogos (ACOG), sobre la base de un limitado número de casos confirmados de COVID-19, reportó que las embarazadas no parecen estar en mayor riesgo de enfermedad grave (6).

La infección usualmente se caracteriza por la presencia de fiebre $(77 \%$ a $85 \%)$, seguida por los síntomas respiratorios (tos seca y disnea en $23 \%$ ), fatiga $\mathrm{y} / \mathrm{o}$ mialgias $\mathrm{y}$, en poca proporción, síntomas gastrointestinales como la diarrea; además se ha comunicado la reducción en el número de leucocitos (leucopenia) y, en especial, linfopenia (7). Algunos reportes describen un mayor riesgo de enfermedad grave en la gestante, mientras que otros no han confirmado estos hallazgos $(8,9)$. Derivado de los resultados de diversos estudios, puede decirse que la gestación, se asocia a un mayor riesgo de infección grave respecto la población no gestante (10)

El riesgo de transmisión vertical no es claro, aunque se dice que es similar al observado en el síndrome respiratorio agudo grave (SARS) $(8,11-15)$.

Las principales complicaciones perinatales se asocian con la prematuridad, la cual es observada en $25 \%$ de los casos, asociada o no, a rotura prematura de membranas (RPM), encontrada en $9 \%(16,17)$.

En el Hospital Central de San Cristóbal, se presentan, con frecuencia, casos de neumonía causada por
SARS-CoV-2, tanto en la población en general, como en la gestante. Sin embargo, la mayoría de los reportes casuísticos y estudios observacionales se centran principalmente en población de adultos, no obstétrica (18).

Se han publicado múltiples investigaciones sobre el tema, entre los que destacan el estudio de Castejón y cols. (19), quienes evaluaron el efecto del SARSCoV-2 sobre la vellosidad placentaria, en una paciente de 29 años de edad quien tuvo COVID-19 a las 36 semanas de embarazo y cuya placenta, descrita con microscopía de luz, presentaba deciduitis y villitis. En 2020, Dávila-Aliaga y cols. (20) evaluaron, las características perinatales, la morbilidad, la mortalidad y los resultados serológicos en neonatos de gestantes seropositivas para SARS-CoV. Akthar y cols. (11) concluyeron que la infección por COVID-19 conduce a un mayor riesgo de complicaciones como parto pretérmino, ruptura prematura de membranas $\mathrm{y}$, posiblemente, puede conducir a la muerte materna en casos raros. Caparros-González (21), a través de una revisión sistemática exploratoria, no identificó una transmisión vertical de madre a hijo, aunque esta información no fue concluyente. Por el contrario, Vivanti y cols. (15) demostraron la transmisión transplacentaria del SARS-CoV-2 en un recién nacido de una madre infectada en el último trimestre, mediante exhaustivas investigaciones virológicas y patológicas.

Con relación a las manifestaciones clínicas de la COVID-19 en las gestantes, Pettirosso y cols. (8) concluyeron que la infección por SARS-CoV-2 durante el embarazo es, a menudo, asintomática y que las tasas de enfermedades graves y críticas se aproximan a las de la población general. En abril de 2020, el ACOG, estableció, sobre la base de un limitado número de casos confirmados de COVID-19, que las embarazadas no parecen estar en mayor riesgo de enfermedad grave (6). Posteriormente, en noviembre de 2020, el ACOG, presentó una actualización sobre COVID- 19 y embarazo (9). 
Los coronavirus constituyen una familia de virus ARN, monocatenario y de cadena positiva, envueltos. Pertenecen a la familia Coronaviridae, subfamilia Orthocoronaviridae, dentro del orden de los Nidovirales (22).

El genoma viral tiene aproximadamente de 27 a 32 kilobases y codifica proteínas estructurales y no estructurales. Entre las estructurales, una de las más importantes en la proteína $\mathrm{S}$, que se proyecta a través de la envoltura viral y forma las espículas de la corona; es la encargada de mediar la unión del receptor (23) (Figura 1).

El primer paso de la infección celular por coronavirus es la unión del virión a receptores en la superficie celular. La glicoproteína S de SARS-CoV-2 se une al receptor celular, que es la enzima convertidora de angiotensina $2(24,25)$.

Algunos autores diferencian tres fases en la enfermedad. En la fase I, el virus se replica en la mucosa respiratoria y ocurre la viremia. En la fase II, la infección llega al pulmón; continúan la tos y la fiebre; la neumonía puede ser leve o cursar con signos de gravedad, el enfermo puede entrar en el estado crítico que caracteriza a la fase III: extrema dificultad respiratoria (requiere respiración asistida) y un

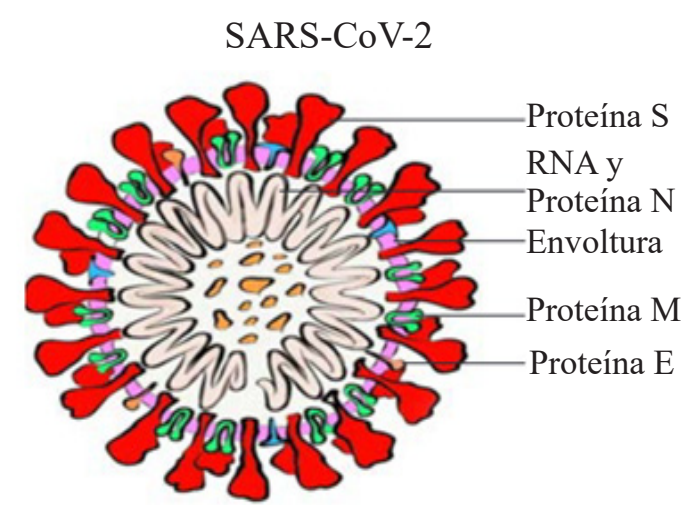

Figura 1. Biología del SARS-CoV-2 (23) cuadro de respuesta inflamatoria sistémica (SIRS, de "Systemic Imflammatory Response Syndrome") (26).

El SARS-CoV-2 podría transmitirse verticalmente de la madre al feto y causar infección clínicamente significativa. Hasta la fecha, el riesgo de contagio intrauterino pareciera ser no significativo y solo ha sido reportado en casos aislados y donde la potencial transmisión horizontal no ha podido ser descartada $(12,13,15,27)$.

Se describen diferentes aspectos relacionados con la enfermedad en la madre. En resumen, la clasificación de caso para embarazadas, tiene en cuenta el criterio clínico y el criterio epidemiológico: criterios de caso 1 , insuficiencia respiratoria aguda (IRA) grave; criterios caso 2, IRA leve; criterios de caso 3 (muerte) y criterio 4 (asintomáticos). Las fases epidemiológicas deben ser una de las variables más importantes para la toma de decisiones con relación a las medidas de contención, mitigación y erradicación de la infección (28).

La detección de ARN de SARS-CoV2 en muestras respiratorias es la técnica de referencia y de elección para el diagnóstico microbiológico de COVID-19. Se toma la muestra de la parte posterior de la faringe y de las fosas nasales y se detecta la presencia del virus (29). La Fundación Internacional de Medicina Materno Fetal (FIMMF) recomienda para el diagnóstico el aspirado nasofaríngeo y el hisopado faríngeo y que toda embarazada para el momento del parto debería ser tamizada al ingreso para COVID-19, con pruebas rápidas, por el riesgo de transmisión vertical y el riesgo del personal de salud (28).

Los datos actuales no sugieren un mayor riesgo de aborto o pérdida gestacional precoz en gestantes con COVID-19. No se han descrito defectos congénitos. La principal complicación perinatal asociada al COVID-19 es la prematuridad, con tasas alrededor del $17 \%$, principalmente a expensas de prematuridad 
iatrogénica. Con relación a los neonatos de madres con COVID-19, si bien el $25 \%$ ingresa en una unidad neonatal, no se han encontrado diferencias significativas con otros resultados perinatales hasta el momento (27).

El feto adquiere la capacidad de producir inmunoglobulinas séricas desde el principio de la gestación. La IgG materna, debido a su peso molecular, se transfiere libremente a través de la placenta por lo que el feto y el neonato muestran buenos niveles de anticuerpos $\operatorname{IgG}$ circulantes transmitidos desde la madre. La IgM materna no atraviesa la barrera placentaria, por lo que se asume que toda $\operatorname{IgM}$ evidenciable en sangre fetal o en cordón umbilical, refleja la respuesta inmunitaria fetal por compromiso infeccioso intrauterino (30).

La presente investigación se realizó para evaluar los resultados maternos y perinatales asociados a la COVID-19 durante la gestación, en mujeres que acudieron al servicio de aislamiento del Hospital Central de San Cristóbal, en el periodo agosto 2020julio 2021.

\section{MÉTODOS}

La investigación, es un estudio retrospectivo o ex post facto, observacional, descriptivo, transversal y el diseño es documental. Es una investigación no experimental, correlacional, de campo. Se incluyeron 30 gestantes, según los siguientes criterios: diagnóstico clínico sospechado o confirmado de COVID-19 con serología y/o PCR-RT (polymerase chain reactionreverse transcription), positiva para SARS CoV-2 o hallazgos clínicos compatibles con la enfermedad. Se excluyeron aquellas cuyas historias clínicas no estaban disponibles para la evaluación.

Previa aprobación de las autoridades correspondientes (Consejo Directivo del Postgrado de Obstetricia y Ginecología de la Facultad de Medicina de la Universidad de Los Andes, y del Comité de Bioética del hospital) se acudió al Departamento de Archivo e Historias Médicas a fin de solicitar las historias de las pacientes seleccionadas para su revisión en la búsqueda de la información que permita cumplir con los objetivos del estudio.

Se calcularon frecuencias absolutas y relativas para las variables cualitativas; además se calcularon mínimos, máximos, promedios, desviaciones estándar y coeficientes de variación de Pearson para las variables continuas. Se establecieron las comparaciones entre los grupos usando el contraste de independencia chi cuadrado de Pearson. Se consideró significativo un resultado asociado a una $\mathrm{p}<0,05$.

\section{RESULTADOS}

Según información proporcionada por el Departamento de Registros Médicos del hospital, entre agosto de 2020 y julio de 2021, ingresaron al hospital 6000 pacientes (500 por mes). En ese periodo, en el Servicio de Aislamiento se registró el ingreso de 30 gestantes con diagnóstico de COVID-19, con lo cual se obtuvo una frecuencia de 0,5 casos de COVID-19 por cada 100 gestantes (1 caso cada 200 gestantes ingresadas). Las 30 pacientes fueron incluidas en el estudio, todas ingresaron con diagnóstico de sospecha según las manifestaciones clínicas y el contacto epidemiológico y a las 30 se les confirmó el diagnóstico mediante una PCR-RT. Dieciséis pacientes (53,3 \%) presentaron enfermedad leve, $5(16,7 \%)$ fueron diagnosticadas como moderadas y $9(30 \%)$, como grave.

Las manifestaciones clínicas de las pacientes, con relación a la COVID-19 se representaron en la tabla 1 . Se observa que las 30 pacientes (100\%) presentaron tos y dificultad respiratoria, $29(96,7 \%)$ tuvieron cefalea y $27(90,0 \%)$ tuvieron fiebre. Con relación a la saturación de oxígeno, 4 pacientes $(13,3 \%)$ tuvieron 
Tabla 1. Distribución de pacientes según las manifestaciones clínicas de la COVID-19

\begin{tabular}{lll}
\hline Manifestaciones clínicas & $\mathrm{n}$ & $\%$ \\
\hline Tos & 30 & 100,0 \\
Dificultad respiratoria & 30 & 100,0 \\
Cefalea & 29 & 96,7 \\
Fiebre & 27 & 90,0 \\
Anosmia & 5 & 16,7 \\
Ageusia & 4 & 13,3 \\
Diarrea & 4 & 13,3 \\
\hline
\end{tabular}

entre $70 \%$ y $79 \%$ y los 26 restantes $(86,7 \%)$, tuvieron la saturación de oxígeno en $90 \%$ o más.

En la tabla 2, se presenta la distribución de pacientes según los valores de las pruebas de laboratorio. Las 30 pacientes tuvieron ferritina elevada, por encima de $200 \mathrm{ng} / \mathrm{dl}, 17$ (56,7 \%) tuvieron leucocitosis, 21 (70\%) tuvieron linfocitos entre $10 \%$ y $15 \%$. El dímero D estuvo elevado en 10 pacientes $(33,3 \%)$ y la lactato deshidrogenasa (LDH) en 27 (90\%).

En la tabla 3 se realizó la distribución de pacientes según los factores de riesgo descritos para evolución grave. Se puede observar que predominaron las pacientes de 25 a 34 años en ambos grupos, entre

Tabla 2. Distribución según las pruebas de laboratorio

\begin{tabular}{lccc}
\hline Pruebas de laboratorio & & $\mathrm{n}$ & $\%$ \\
\hline Ferritina (ng/dl) & $>200$ & 30 & 100,0 \\
Leucocitos $\left(\mathrm{x} \mathrm{mm}^{3}\right)$ & $<10000$ & 17 & 56,7 \\
& $\geq 10000$ & 13 & 43,3 \\
Linfocitos (\%) & $10-11$ & 13 & 43,3 \\
& $12-13$ & 5 & 16,7 \\
& $14-15$ & 3 & 10,0 \\
& $16-17$ & 1 & 3,3 \\
& $18-19$ & 8 & 26,7 \\
Dímero D (ng/mL) & $<300$ & 20 & 66,7 \\
& $\geq 300$ & 10 & 33,3 \\
LDH (U/L) & $60-160$ & 3 & 10,0 \\
& $>160$ & 27 & 90,0 \\
\hline
\end{tabular}

Tabla 3. Distribución de pacientes según factores de riesgo para evolución grave

\begin{tabular}{|c|c|c|c|c|c|}
\hline \multirow{2}{*}{ Factor de riesgo } & \multicolumn{2}{|c|}{ Evolución grave } & \multicolumn{2}{|c|}{ Evolución no grave } & \multirow{2}{*}{$\mathrm{p}$} \\
\hline & $\mathrm{n}$ & $\%$ & $\mathrm{n}$ & $\%$ & \\
\hline $\begin{array}{l}\text { Edad materna } \\
\text { (años) }\end{array}$ & & & & & 0,961 \\
\hline$<25$ & 1 & 11,1 & 3 & 14,3 & \\
\hline $25-34$ & 6 & 66,7 & 14 & 66,7 & \\
\hline 35 y más & 2 & 22,2 & 4 & 19,0 & \\
\hline Edad gestacional & & & & & 0,589 \\
\hline Primer trimestre & 0 & 0,0 & 1 & 4,8 & \\
\hline Segundo trimestre & 3 & 33,3 & 4 & 19,0 & \\
\hline Tercer trimestre & 6 & 66,7 & 16 & 76,2 & \\
\hline $\begin{array}{l}\text { Índice de masa } \\
\text { corporal }\end{array}$ & & & & & 0,238 \\
\hline Normal & 1 & 11,1 & 1 & 4,8 & \\
\hline Sobrepeso & 5 & 55,6 & 6 & 28,6 & \\
\hline Obesidad & 3 & 33,3 & 14 & 66,7 & \\
\hline Etnia & & & & & ---- \\
\hline Mestiza & 9 & 100,0 & 21 & 100,0 & \\
\hline Comorbilidades & & & & & 1,000 \\
\hline $\mathrm{Si}$ & 6 & 66,7 & 13 & 61,9 & \\
\hline No & 3 & 33,3 & 8 & 38,1 & \\
\hline Anemia & & & & & 0,576 \\
\hline $\mathrm{Si}$ & 6 & 66,7 & 10 & 47,6 & \\
\hline No & 3 & 33,3 & 11 & 52,4 & \\
\hline $\begin{array}{l}\text { Hipertensión arterial } \\
\text { crónica }\end{array}$ & & & & & 0,873 \\
\hline $\mathrm{Si}$ & 0 & 0,0 & 2 & 9,5 & \\
\hline No & 9 & 100,0 & 19 & 90,5 & \\
\hline Diabetes mellitus & & & & & 0,873 \\
\hline $\mathrm{Si}$ & 0 & 0,0 & 2 & 9,5 & \\
\hline No & 9 & 100,0 & 19 & 90,5 & \\
\hline
\end{tabular}

las que tuvieron evolución grave fueron 6 pacientes $(66,7 \%)$ y entre las que tuvieron evolución leve o moderada fueron $14(66,7 \%)$. Una paciente diagnosticada en el primer trimestre presentó evolución leve, igualmente, 4 en el segundo trimestre $(28,6 \%)$ y 16 en el tercer trimestre $(76,2 \%)$. Entre las que tuvieron evolución grave, $3(33,3 \%)$ estaban en el segundo trimestre y 6 en el tercero $(66,7 \%)$. 
No hubo asociación estadística entre la evolución grave de la enfermedad y la edad materna $(\mathrm{p}=0,961)$, la edad gestacional $(\mathrm{p}=0,589)$, el índice de masa corporal $(\mathrm{p}=0,238)$ ni la presencia de comorbilidades $(\mathrm{p}=1,000)$; tampoco se encontró asociación cuando se evaluaron las distintas comorbilidades: anemia $(\mathrm{p}=0,576)$, hipertensión arterial crónica $(\mathrm{p}=0,873)$, ni diabetes mellitus $(p=0,873)$, es decir, ninguna de estas variables se comportó como factor de riesgo para evolución grave.

En las tablas 4 y 5 se presenta la distribución según la evolución del embarazo y según la evolución de la enfermedad.

Solo tres embarazos (10 \%) evolucionaron sin complicaciones. Entre los 27 restantes (90\%) se presentaron las siguientes complicaciones: 12 (40,0\%) parto pretérmino, $11(36,7 \%)$ oligohidramnios y 6 amenazas de parto pretérmino (20\%). Las otras complicaciones se presentan en la tabla. Destacan 6 muertes maternas $(20,0 \%)$ y 2 óbitos fetales $(6,7 \%)$.

Tabla 4. Distribución de pacientes según la evolución del embarazo

\begin{tabular}{lcc}
\hline Evolución del embarazo & Pacientes & $\%$ \\
\hline Sin complicaciones & 3 & 10,0 \\
Con complicaciones & 27 & 90,0 \\
$\quad$ Parto pretérmino & 12 & 40,0 \\
Oligohidramnios & 11 & 36,7 \\
Muerte materna & 6 & 20,0 \\
Amenaza de parto pretérmino & 6 & 20,0 \\
Óbito fetal & 2 & 6,7 \\
Ruptura prematura de membranas & 2 & 6,7 \\
Crecimiento fetal restringido & 2 & 6,7 \\
Trastorno hipertensivo del & 2 & 6,7 \\
embarazo & 1 & 3,3 \\
Aborto & 1 & 3,3 \\
Placenta previa &
\end{tabular}

Tabla 5. Distribución de pacientes según la evolución de la COVID-19

\begin{tabular}{lcc}
\hline Evolución de la COVID-19 & Pacientes & $\%$ \\
\hline Satisfactoria & 16 & 53,3 \\
Insatisfactoria & 14 & 46,7 \\
Ingreso a terapia & & \\
$\quad \mathrm{Si}$ & 12 & 40,0 \\
$\quad$ No & 18 & 60,0 \\
Apoyo ventilatorio & & \\
$\quad$ Si & 9 & 30,0 \\
$\quad$ No & 21 & 70,0 \\
Condiciones de egreso & & \\
$\quad$ Buenas & 21 & 70,0 \\
$\quad$ Con secuelas & 3 & 10,0 \\
$\quad$ Muerte materna & 6 & 20,0 \\
\hline
\end{tabular}

En 16 casos (53,3\%), la evolución de la enfermedad fue satisfactoria, es decir, no hubo complicaciones. En $14(46,7 \%)$ hubo complicaciones, por lo que fueron catalogadas como evolución insatisfactoria. Todas las pacientes fueron hospitalizadas, 12 (40\%) fueron ingresadas a la unidad de terapia intensiva y $9(30,0 \%)$ de ellas requirieron apoyo ventilatorio. La duración media de la hospitalización fue de 7,63 $\pm 6,45$ días, con extremos de 2 y 30 días. La permanencia en la unidad de terapia intensiva tuvo una media de 10,08 $\pm 8,62$ con un mínimo de 2 y máximo de 30 días. Así mismo, el apoyo ventilatorio fue necesario en 8,50 \pm 7,62 días con extremos de 2 y 20 días. Al momento del egreso, 21 mujeres (70\%) estaban en buenas condiciones, 3 $(10,0 \%)$ egresaron con secuelas y, como ya se señaló, hubo 6 muertes maternas $(20,0 \%)$ como consecuencia de la enfermedad.

Se evaluó la relación entre la evolución clínica de la COVID-19 y la presencia de patologías propias y asociadas al embarazo y se presentan en las tablas 6 y 7 .

En el primer trimestre, entre las que tuvieron evolución satisfactoria de la enfermedad, solo hubo 
Tabla 6. Distribución según la relación entre evolución de la COVID-19 y la presencia de patologías propias del embarazo

\begin{tabular}{|c|c|c|c|c|c|}
\hline \multirow[t]{2}{*}{$\begin{array}{l}\text { Patologías propias } \\
\text { del embarazo }\end{array}$} & \multicolumn{2}{|c|}{$\begin{array}{c}\text { Evolución } \\
\text { satisfactoria } \\
n=16\end{array}$} & \multicolumn{2}{|c|}{$\begin{array}{c}\text { Evolución no } \\
\text { satisfactoria } \\
n=14\end{array}$} & \multirow[t]{2}{*}{$\mathrm{p}$} \\
\hline & $\mathrm{n}$ & $\%$ & $\mathrm{n}$ & $\%$ & \\
\hline Primer trimestre & & & & 1,000 & 0,961 \\
\hline Aborto & 1 & 6,3 & 0 & 0,0 & \\
\hline Ninguna & 15 & 93,8 & 14 & 100,0 & \\
\hline Segundo trimestre & & & & & 0,112 \\
\hline Parto pretérmino & 0 & 0,0 & 4 & 28,6 & \\
\hline Oligohidramnios & 7 & 43,8 & 4 & 28,6 & \\
\hline Placenta previa & 1 & 6,3 & 0 & 0,0 & \\
\hline Ninguna & 8 & 50,0 & 6 & 42,9 & \\
\hline Tercer trimestre & & & & 0,319 & 0,238 \\
\hline Parto pretérmino & 3 & 18,8 & 5 & 35,7 & \\
\hline $\begin{array}{l}\text { Trastornos } \\
\text { hipertensivos } \\
\text { del embarazo }\end{array}$ & 2 & 12,5 & 0 & 0,0 & \\
\hline Oligohidramnios & 7 & 43,8 & 4 & 28,6 & \\
\hline Placenta previa & 1 & 6,3 & 0 & 0,0 & \\
\hline Ninguna & 3 & 18,8 & 5 & 35,7 & \\
\hline
\end{tabular}

un caso de aborto $(6,3 \%)$. Las otras 15 pacientes con evolución satisfactoria y las 14 con evolución no satisfactoria, no presentaron patologías propias del embarazo en el primer trimestre $(p=1,000)$. En el segundo trimestre, entre las 16 pacientes con evolución satisfactoria hubo 7 casos de oligohidramnios $(43,8 \%)$ y un caso de placenta previa (6,3\% cada uno). Entre las 14 pacientes con evolución no satisfactoria también hubo 4 casos de oligohidramnios $(28,6 \%), 4$ de parto pretérmino $(28,6 \%)(p=0,112)$. En el tercer trimestre, se observaron 2 casos de trastornos hipertensivos del embarazo $(12,5 \%)$ en el grupo de evolución satisfactoria $(\mathrm{p}=0,319)$ y 3 partos pretérmino $(18,8 \%)$, así mismo, hubo 5 partos pretérmino en el grupo con evolución no satisfactoria $(35,7 \%)$. No hubo patologías propias durante el parto ni en el puerperio.
Tabla 7. Distribución según la relación entre evolución de la COVID-19 y la presencia de patologías asociadas al embarazo

\begin{tabular}{|c|c|c|c|c|c|}
\hline \multirow[t]{2}{*}{$\begin{array}{l}\text { Patologías propias } \\
\text { del embarazo }\end{array}$} & \multicolumn{2}{|c|}{$\begin{array}{c}\text { Evolución } \\
\text { satisfactoria } \\
n=16\end{array}$} & \multicolumn{2}{|c|}{$\begin{array}{c}\text { Evolución no } \\
\text { satisfactoria } \\
n=14\end{array}$} & \multirow[t]{2}{*}{$\mathrm{p}$} \\
\hline & $\mathrm{n}$ & $\%$ & $\mathrm{n}$ & $\%$ & \\
\hline Cardiovascular & & & & & 0,525 \\
\hline $\mathrm{Si}$ & 2 & 12,5 & 0 & 0,0 & \\
\hline No & 14 & 87,5 & 14 & 100,0 & \\
\hline Endocrinológica & & & & 1,000 & 0,112 \\
\hline $\begin{array}{l}\text { Diabetes } \\
\text { pregestacional }\end{array}$ & 1 & 6,3 & 1 & 7,1 & \\
\hline Ninguna & 15 & 93,8 & 13 & 92,9 & \\
\hline Hematológicas & & & & & 0,272 \\
\hline Anemias & 6 & 37,5 & 9 & 64,3 & \\
\hline Ninguna & 10 & 62,5 & 5 & 35,7 & \\
\hline Infecciosas & & & & & 0,192 \\
\hline $\begin{array}{l}\text { Vaginosis } \\
\text { bacteriana }\end{array}$ & 3 & 18,8 & 0 & 0,0 & \\
\hline $\begin{array}{l}\text { Infección de tracto } \\
\text { urinario }\end{array}$ & 2 & 12,5 & 2 & 14,3 & \\
\hline Sepsis & 0 & 0,0 & 1 & 7,1 & \\
\hline Toxoplasma & 0 & 0,0 & 2 & 14,3 & \\
\hline Ninguna & 11 & 68,8 & 9 & 64,3 & \\
\hline Otras & & & & & 1,000 \\
\hline Hipoalbuminemia & 1 & 6,3 & 1 & 7,1 & \\
\hline Sin patología & 15 & 93,8 & 13 & 92,9 & \\
\hline
\end{tabular}

Con relación a las patologías asociadas a la gestación, en el grupo que tuvo evolución satisfactoria de la COVID-19 destacan 2 patologías cardiovasculares $(12,5 \%), 1$ diabetes pregestacional $(6,3 \%), 6$ casos de anemia $(37,5 \%)$ y 5 infecciones: 3 vaginosis bacteriana $(18,8 \%)$ y 2 infecciones del tracto urinario (ITU) $(12,5 \%)$. En el grupo de las que tuvieron evolución no satisfactoria, se diagnosticó una diabetes gestacional (7,1\%), 9 casos de anemia $(64,3 \%)$ y 5 infecciones: 2 infecciones del trato urinario $(14,3 \%)$, 2 toxoplasmosis $(14,3 \%)$ y una sepsis $(7,1 \%)$. No hubo relación entre la evolución de la enfermedad COVID-19 y la presencia de patologías asociadas al embarazo. 
M P CASTRO ÁÑEZ ET AL.

Tabla 8. Distribución de la vía de resolución obstétrica según la evolución de la COVID-19

\begin{tabular}{lcccccccc}
\hline \multirow{2}{*}{ Evolución de la COVID-19 } & \multicolumn{2}{c}{ Parto vaginal } & Cesárea & \multicolumn{2}{c}{ Aborto } & \multirow{2}{*}{$\mathrm{p}$} \\
\cline { 2 - 6 } & $\mathrm{n}$ & $\%$ & & & $\mathrm{n}$ & $\%$ & \\
\hline Evolución general & 2 & 66,7 & 13 & 50,0 & 1 & 100,0 & \\
$\quad$ Satisfactoria & 1 & 33,3 & 13 & 50,0 & 0 & 0,0 & \\
$\quad$ Insatisfactoria & & & & & & & 0,000 \\
Ingreso a UCI & 1 & 33,3 & 11 & 42,3 & 0 & 0,0 & \\
Si & 2 & 66,7 & 15 & 57,7 & 1 & 100,0 & \\
No & & & & & & & 0,000 \\
Apoyo ventilatorio & 1 & 33,3 & 9 & 34,6 & 0 & 0,0 & \\
Si & 2 & 66,7 & 17 & 65,4 & 1 & 100,0 & \\
No & & & & & & & 0,001 \\
Condiciones de egreso & 2 & 66,7 & 18 & 69,2 & 1 & 100,0 & \\
Buenas & 0 & 0,0 & 3 & 11,5 & 0 & 0,0 & \\
Con secuelas & 1 & 33,3 & 5 & 19,2 & 0 & 0,0 & \\
$\quad$ Muerte materna & & & & & &
\end{tabular}

En la tabla 8 se describe la vía de resolución obstétrica según la evolución de la enfermedad. En general, hubo 3 partos, 26 cesáreas y un legrado. Dos pacientes con parto vaginal $(66,7 \%)$ presentaron evolución satisfactoria y $1 \quad(33,3 \%)$ presentó evolución insatisfactoria; entre las pacientes a quienes se les practicó cesárea $13(50 \%)$ tuvieron evolución satisfactoria y las otras $13(50 \%)$ no satisfactoria. La paciente con el aborto tuvo evolución satisfactoria de la enfermedad $(\mathrm{p}=0,000)$. Una paciente con parto vaginal requirió ingreso a terapia y apoyo ventilatorio (33,3\%); la media de permanencia en terapia y de apoyo ventilatorio fue de $2 \pm 0$ días. Entre las de cesárea, 11 $(42,3 \%)$ ingresaron a terapia y 9 necesitaron apoyo ventilatorio $(\mathrm{p}=0,000)$; la media de ingreso a terapia fue de 10,8 $\pm 8,6$ días y de apoyo ventilatorio, 9,2 $\pm 7,7$ días. En cuanto a las condiciones de egreso, 2 pacientes con parto vaginal egresaron en buenas condiciones $(66,7 \%)$ y la paciente restante falleció $(33,3 \%)$. En el grupo de las pacientes a quienes se les practicó cesárea, 18 egresaron en buenas condiciones $(69,2 \%), 3$ con secuelas $(11,5 \%)$ y hubo 5 fallecidas $(19,2 \%)(p=0,001)$.
Finalmente, en la tabla 9 se puede observar la evolución perinatal. Entre los 27 recién nacidos (RN) (se excluyeron el aborto y los dos óbitos fetales), 19 (70,4 \%) presentaron una puntuación de Apgar al minuto entre 7 y 8 y $22 \mathrm{RN}(81,4 \%)$ tuvieron un Apgar a los 5 minutos entre 7 y 9 puntos. Considerando los 29 casos, 20 tuvieron un peso adecuado para la edad gestacional y 24 tuvieron una talla adecuada para la edad gestacional. La media de peso fue $2323,5 \pm 802,6$ gramos, con extremos de 700 y 3400 gramos. La media de talla fue 44,14 $\pm 8,07 \mathrm{~cm}$, con una talla mínima de 23 y máxima de $51 \mathrm{~cm}$. El aborto ocurrió en el primer trimestre, hubo 12 recién nacidos $(\mathrm{RN})$ prematuros (40\%) y 17 a término (63\%). Se hospitalizaron 10 $\mathrm{RN}(37 \%)$ y 7 (70 \%) de ellos solo necesitaron entre 1 y 4 días de hospitalización. Los $10 \mathrm{RN}$ hospitalizados requirieron ingreso a la unidad de terapia intensiva neonatal por una media de 5,5 $\pm 5,43$ días. Al egreso, 21 estaban en buenas condiciones (70\%), 1 con secuelas $(3,3 \%)$, todos con PCR-RT negativa para SARS-CoV-2. Se contabilizaron 5 muertes neonatales $(16,7 \%)$ y 2 óbitos fetales $(6,7 \%)$, además del aborto descrito. 
Tabla 9. Distribución de pacientes según el resultado perinatal

\begin{tabular}{|c|c|c|}
\hline Evolución del embarazo & Pacientes & $\%$ \\
\hline \multicolumn{3}{|l|}{ Apgar al minuto $1 *$} \\
\hline $3-4$ & 2 & 7,4 \\
\hline $5-6$ & 6 & 22,2 \\
\hline $7-8$ & 19 & 70,4 \\
\hline \multicolumn{3}{|l|}{ Apgar al minuto $5^{*}$} \\
\hline $3-4$ & 2 & 7,4 \\
\hline $5-6$ & 3 & 11,1 \\
\hline $7-8$ & 10 & 37,0 \\
\hline 9 & 12 & 44,4 \\
\hline \multicolumn{3}{|l|}{ Peso** } \\
\hline Adecuado para edad gestacional & 20 & 69,0 \\
\hline Bajo para edad gestacional & 9 & 31,0 \\
\hline \multicolumn{3}{|l|}{ Talla** } \\
\hline Adecuado para edad gestacional & 24 & 82,8 \\
\hline Bajo para edad gestacional & 5 & 17,2 \\
\hline \multicolumn{3}{|l|}{ Edad gestacional $* * *$} \\
\hline Aborto & 1 & 3,3 \\
\hline Pretérmino & 12 & 40,0 \\
\hline A término & 17 & 56,7 \\
\hline \multicolumn{3}{|l|}{ Hospitalización* } \\
\hline $\mathrm{Si}$ & 10 & 37,0 \\
\hline No & 17 & 63,0 \\
\hline \multicolumn{3}{|l|}{ Días de hospitalización ${ }^{* * * *}$} \\
\hline $1-4$ & 7 & 70,0 \\
\hline $5-9$ & 1 & 10,0 \\
\hline 10 o más & 2 & 20,0 \\
\hline \multicolumn{3}{|l|}{ Diagnóstico del pediatra** } \\
\hline Pequeño para la EG & 9 & 31,0 \\
\hline Adecuado para la EG & 20 & 69,0 \\
\hline \multicolumn{3}{|l|}{ Ingreso a UCIN** } \\
\hline $\mathrm{Si}$ & 10 & 34,5 \\
\hline No & 19 & 65,5 \\
\hline \multicolumn{3}{|l|}{ Condiciones de egreso $* * *$} \\
\hline Buenas & 21 & 70,0 \\
\hline Con secuelas & 1 & 3,3 \\
\hline Muertes neonatales & 5 & 16,7 \\
\hline Óbitos fetales & 2 & 6,7 \\
\hline Aborto & 1 & 3,3 \\
\hline
\end{tabular}

* 27 pacientes, se excluyen abortos y óbitos fetales;

** 29 pacientes, se excluyen abortos; *** 30 pacientes, no se excluye ningún paciente; $* * * * 10$ pacientes

\section{DISCUSIÓN}

Esta investigación se realizó con la finalidad de evaluar la evolución materna y perinatal asociada a la COVID-19, ya que el 13 de marzo de 2020, la OMS la reconoció como pandemia (3 - 5) y como era de esperar, a medida que aumentó el número de casos infectados, aparecieron más casos de COVID-19 en embarazadas. Sin embargo, en el país hay pocos reportes de la enfermedad, asociada a la gestación, que evalúen la evolución materna y perinatal. En abril de 2020, el ACOG, reportó que las embarazadas no parecen estar en mayor riesgo de enfermedad grave (6). Sin embargo, a medida que se presentan más casos, van surgiendo informes contradictorios que hacen imperativo evaluar los casos autóctonos para identificar la real evolución materna y perinatal en la población.

La prevalencia registrada en el periodo fue del 0,5\%, es decir, 1 de cada 200 gestantes ingresó en el periodo de estudio con el diagnóstico de COVID-19. Estas cifras, si bien no son muy elevadas, obligan a estar alertas ante la presencia de síntomas y a descartar el diagnóstico ante la menor sospecha. En el presente estudio se incluyó un total de 30 pacientes que acudieron y estuvieron hospitalizadas en el área del aislamiento del Hospital Central de San Cristóbal, todas las pacientes del estudio fueron diagnosticadas mediante la PCR-RT, además todas manifestaron contacto epidemiológico y diferentes manifestaciones clínicas.

Cabe destacar que la técnica más utilizadas para el diagnóstico es PCR (polymerase chain reaction, reacción en cadena de la polimerasa), la cual es una técnica utilizada de manera rutinaria en todos los laboratorios clínicos y que está basada en la amplificación de fragmentos de ADN (31), para ello, es necesario que el ARN vírico sea primero convertirlo en ADN por la transcripción inversa, (RT reverse transcription) y, a partir de eso, se inicia la PCR (32). 
Según Pérez-Wulff y cols. (33), la prueba de ácido nucleico es el método preferido para diagnosticar la infección por SARS-CoV-2. Las muestras son preprocesadas y el virus se lisa para extraer ácidos nucleicos. Los tres genes específicos de SARS-CoV-2, el brazo de lectura libre (ORFla/b), la proteína de la nucleocápside $(\mathrm{N})$ y los genes de la proteína de envoltura (E), son amplificados por reacción en cadena de polimerasa cuantitativa en tiempo real (PCR-RT) y detectados según la intensidad de su fluorescencia. Para pacientes con sospecha de infección se debe realizar fluorescencia en tiempo real (PCR-RT) para detectar el ácido nucleico positivo del SARS-CoV-2 y se ha sugerido obtener las muestras a través de frotis nasofaríngeo, esputo, hisopado de garganta y secreciones del tracto respiratorio inferior. La muestra obtenida por frotis nasofaríngeo para detección de SARS-CoV-2 representa la opción más recomendable. Puesto que este es el método de laboratorio por excelencia para confirmar el diagnóstico, fue utilizado en todas las gestantes que ingresaron y tenían síntomas y/o contacto epidemiológico, de manera que todos los casos sospechados fueron confirmados. Se debe tener en cuenta que los casos sospechosos o sospechados se refieren a toda embarazada con síntomas respiratorios (rinorrea, estornudos, tos seca) y/o fiebre, malestar general o fatiga, diarrea (en algunas ocasiones) en quien debe considerarse el diagnóstico de COVID-19 hasta no demostrar lo contrario, además el nexo epidemiológico y los antecedentes de viajes ayudan, pero en la transmisión comunitaria son irrelevantes. Los casos confirmados se refieren a tres situaciones específicas;a)embarazada con prueba positivamediante reacción en cadena de polimerasa por transcriptasa reversa en tiempo real ( $\mathrm{PCR}-\mathrm{RT}$ ), o pruebas rápidas; b) Síntomas más hallazgos radiológicos; c) Síntomas respiratorios y nexo epidemiológico (Clasificación de caso confirmado de Wuhan) (34).

Entre las manifestaciones clínicas, se observó que la tos y la dificultad respiratoria se encontraron en todas las pacientes estudiadas y la cefalea y la fiebre estuvieron presentes en el $90 \%$ de la muestra o más.
Se ha descrito que las gestantes sintomáticas refieren clínica compatible con la que presenta la población general, la mayoría cursa con síntomas leves $(80 \%)$. En orden de frecuencia, la sintomatología asociada a las infecciones leves es la siguiente: fiebre $(90 \%)$, tos seca $(76 \%)$, mialgias (44\%), tos con expectoración (28\%), cefalea $(8 \%)$ y diarrea $(3 \%)(16,33-35)$ reportaron, en 2020 que las manifestaciones más frecuentes en los pacientes con COVID-19 son: fiebre, reportada en más de $90 \%$ de los casos, otros síntomas incluyen tos seca, fatiga o debilidad, cefalea, disnea y diarrea en algunos casos. Los resultados de esta serie se correlacionan bien con los reportados por estos autores (33).

Se consideran marcadores analíticos de gravedad y con valor pronóstico la $\mathrm{LDH}$, ferritina, troponina-I y dímero-D. Las 30 pacientes tuvieron ferritina elevada, por encima de $200 \mathrm{ng} / \mathrm{dl}, 27$ tuvieron elevación de la LDH (90\%), 21 (70\%) tuvieron linfocitos entre $10 \%$ y $15 \%$ y 17 (56,7 \%) tuvieron leucocitosis. El dímero D estuvo elevado en 10 pacientes (33,3\%). La LDH, proteína $\mathrm{C}$ reactiva, ferritina y dímero $\mathrm{D}$ elevados, linfopenia, plaquetas $<150000 \mathrm{y}$ anormalidad en la función renal se consideran datos de laboratorio de mal pronóstico, sin embargo, hay que tener en cuenta que el dímero $\mathrm{D}$ en las embarazadas aumenta en cada trimestre (34).

Se puede observar que cerca de la mitad de las pacientes $(53,3 \%)$ presentaron enfermedad leve, un pequeño porcentaje $(16,7 \%)$ fueron diagnosticadas como moderadas y $30 \%$, como grave. Los datos disponibles sugieren que las embarazadas sintomáticas con COVID-19 tienen un mayor riesgo de padecer enfermedad más grave, en comparación con sus pares no embarazadas, porque la patogenia de estas infecciones se ve afectada por los cambios fisiológicos del embarazo, tales como la actividad reducida de las células asesinas naturales (natural killer), los macrófagos inflamatorios y las células T. Además, los factores mecánicos y bioquímicos afectan el intercambio de gases y la función pulmonar 
durante el embarazo; la capacidad residual funcional y el volumen residual disminuyen en el embarazo especialmente en el tercer trimestre; estos cambios implican mayor vulnerabilidad a tener enfermedad del tracto respiratorio más grave, sobre todo las últimas semanas del embarazo. En epidemias y pandemias de influenza las embarazadas han mostrado enfermedad grave, evolución adversa del embarazo y muerte materna (35). Dada la creciente evidencia, el CDC (Centers for Disease Control and Prevention) incluye a las gestantes en su categoría de "mayor riesgo" de enfermedad de COVID-19. Aunque el riesgo absoluto de COVID-19 grave es bajo, estos datos indican un mayor riesgo de ingreso en la unidad de cuidados intensivos (UCI), necesidad de ventilación mecánica y soporte ventilatorio y de muerte materna por COVID-19, en comparación con las mujeres sintomáticas no embarazadas (9).

Se han descrito como factores de riesgo en COVID-19, la enfermedad cardiovascular, diabetes mellitus (DM), enfermedad pulmonar obstructiva crónica (EPOC)/enfermedad pulmonar, hipertensión arterial (HTA), insuficiencia renal crónica (IRC), cáncer, inmunosupresión, incluyendo infección por virus de inmunodeficiencia humana (VIH) en etapa de SIDA (síndrome de inmunodeficiencia adquirida), asma, embolismo pulmonar previo, preeclampsia, eclampsia o alguna patología que requiera consulta por alto riesgo obstétrico (ARO) (34). También se han estudiado los factores de riesgo de complicaciones y destacan las comorbilidades preexistentes, la etnia no blanca, la hipertensión crónica, la diabetes preexistente, la edad materna avanzada y el alto índice de masa corporal $(10,36)$. Al evaluar los factores de riesgo en este grupo de pacientes, no se encontró relación entre los mismos y la evolución de la COVID-19. No hubo asociación estadística entre la evolución grave de la enfermedad y la edad materna, la edad gestacional, el índice de masa corporal, ni la presencia de comorbilidades, habiéndose evaluado anemia, hipertensión arterial crónica y diabetes mellitus, es decir, ninguna de estas variables se comportó como factor de riesgo para evolución grave.
En este grupo, el embarazo presentó complicaciones en el $90 \%$ de las pacientes. Las más frecuentes fueron parto pretérmino y oligohidramnios, incluyendo una elevada frecuencia de amenaza de parto pretérmino que, afortunadamente, pudo ser revertida en la mayoría de los casos. Se ha descrito que hay evidencias de que la infección cursa con evolución adversa del embarazo, tales como aborto, parto prematuro y muerte materna. Se cree que los partos prematuros están relacionados con la oxigenación fetal deficiente, que experimenta el $80 \%$ de esas gestantes durante su segundo y tercer trimestre (35). Otros autores han reportado la elevada frecuencia de parto pretérmino entre las gestantes con COVID-19 (10, 11, 20, 36, 37). En esta serie hubo 12 casos, lo que representó una frecuencia del $40 \%$, bastante más elevada que la tasa general para la población obstétrica que se encuentra alrededor del $12,6 \%$ (38).

Con relación a la enfermedad COVID-19, esta evolucionó en forma satisfactoria en el 53,3\% de las pacientes, es decir, que cerca de la mitad de las gestantes tuvieron una evolución no satisfactoria de su enfermedad, dada por la necesidad de ingreso a la unidad de cuidados intensivos (40\%), en su mayoría para recibir apoyo ventilatorio $(30 \%)$. Las complicaciones maternas pueden incluir la neumonía y el deterioro progresivo que, en caso de presentarse, se deben clasificar según el q-SOFA (Quick Sequential Organ Failure Assessment) para determinar su necesidad de ingreso a la unidad de cuidados intensivos y de ventilación invasiva mecánica con manejo multidisciplinario (33). Habiéndose cumplido el protocolo establecido, el $70 \%$ de las pacientes egresó en buenas condiciones generales, aunque, desafortunadamente, un porcentaje de casi el 10,0\% egresó con secuelas y 6 gestantes fallecieron, para una letalidad de la enfermedad del 20,0\%. Allotey y cols. (10), reportaron que las gestantes son menos propensas a manifestar síntomas como fiebre, disnea y mialgias, pero son más propensas que las no embarazadas en edad reproductiva a ser ingresadas en la unidad de cuidados intensivos o a necesitar ventilación invasiva. La Organización Panamericana 
de la Salud/Organización Mundial de la Salud (OPS/ OMS) también reportó que existe un mayor riesgo de la gestante de presentar formas graves de COVID-19 y por ende de ser hospitalizadas y admitidas a unidades de cuidados intensivos (39).

En este grupo de pacientes no se encontró asociación entre la evolución de la COVID-19 y la presencia de patologías propias del embarazo. En el primer trimestre hubo un caso de aborto en una paciente con cuadro leve de COVID-19, en el segundo y el tercer trimestre lo más llamativo fue la presencia de oligohidramnios, que se presentó por igual entre casos complicados y no complicados. Los partos pretérminos se presentaron 4 en el segundo trimestre y 8 en el tercero; 3 de ellos se asociaron a evolución satisfactoria de la enfermedad y 9 a evolución no satisfactoria. Como se señaló previamente, se ha relacionado la COVID-19 con evolución adversa del embarazo, pero no se ha establecido con certeza si la presencia de patologías propias del embarazo se asocie a evolución más grave de la enfermedad.

Así mismo, se investigó si existía relación entre la evolución de la COVID-19 y la presencia de patologías asociadas a la gestación, esto es, comorbilidades. Tal relación no fue observada en forma general, ni cuando se evaluó cada patología en forma independiente. Como se describió al discutir sobre los factores de riesgo para evolución adversa de la enfermedad, las comorbilidades preexistentes parecen estar asociadas a evolución grave $(10,36)$, aunque en esta serie no se pudo demostrar.

La tasa de cesárea fue de 86,7 \% (10 \% de partos vaginales y $3,3 \%$ de legrados por aborto). La OMS ha establecido recomendaciones internacionales acerca de la tasa de cesárea óptima, que no debe sobrepasar el $15 \%$, para que los países se guíen y puedan fijar sus metas de salud materna a largo plazo (40). La intervención por cesárea, cuando está justificada, es eficaz para prevenir la morbimortalidad materna y perinatal, sin embargo, la OMS informó que desde el siglo anterior, los especialistas en la salud materna y fetal a nivel mundial han determinado que una tasa ideal de cesárea no debe exceder entre el $10 \%$ y el $15 \%$ y que no están demostrados los beneficios de la cesárea en pacientes donde este procedimiento es innecesario (40).

Es evidente que la tasa de cesáreas en el mundo se ha incrementado y en varios países de América Latina se encuentran porcentajes elevados de cesáreas. Chile, Paraguay, Uruguay, Colombia, Ecuador y Venezuela tienen tasas entre el $25,1 \%$ y el $35 \%$, rebasando los límites recomendados por los consensos científicos internacionales (40). La tasa de $86,7 \%$ resulta muy elevada, aun considerando que se trata de pacientes con una enfermedad como la COVID-19. Según recomendaciones de la Sociedad Venezolana de Obstetricia y Ginecología (SOGV) (33), la decisión de la vía de finalización, en pacientes con COVID-19, dependerá de la condición del embarazo y del feto (indicación obstétrica) y debe tomarse en cuenta la edad gestacional. La resolución por cesárea, se recomienda solo en pacientes que tengan una indicación obstétrica previa o que presenten alguna emergencia. El acto quirúrgico debe evitarse a menos que sea estrictamente necesario y se debe tomar en cuenta todas las medidas de prevención posibles $(33,34)$. Otros autores han señalado que la vía del parto de elección en una situación clínica materna grave o crítica será la cesárea (27), aunque, como regla general, la decisión debe tomarse según la situación obstétrica (41). A pesar de esto, Dubey y cols. (37) reportaron que los resultados sobre las madres y los neonatos incluyeron, entre otros, un aumento de cesáreas como modalidad de parto. Entre las 26 pacientes a quienes se les practicó cesárea, la mitad tenían evolución satisfactoria de la enfermedad, es decir, casos leves o moderados y la otra mitad tenían casos graves. Valdría la pena revisar las indicaciones de la cesárea en esos casos, a manera de reflexión. Aunque la comunidad médica, en general, y los ginecoobstetras, en forma específica, han aprendido mucho sobre la COVID-19 en el transcurso de los últimos dos años, sigue tratándose de una enfermedad 
nueva, en gran parte todavía desconocida; tal vez esto, aunado a la preocupación por la evolución de la madre y al elevado riesgo de contagio durante la atención del parto vaginal, explique la frecuencia elevada de culminación de la gestación por vía alta.

Al evaluar la evolución perinatal, se encontró que 21 recién nacidos evolucionaron en forma satisfactoria; eso representó el $70 \%$ de los casos totales. Las puntuaciones del Apgar al minuto y a los 5 minutos y los pesos y tallas al nacer se correlacionan bien con esa evolución. Como se ha venido señalando, hubo 12 prematuros (40\%) y $10 \mathrm{RN}$ ameritaron ingresar a la unidad de cuidados intensivos neonatales. La tasa de mortalidad perinatal fue de 23,3 \% (2 óbitos fetales y 5 muertes neonatales). Dávila-Aliaga y cols. (20), señalaron una frecuencia de muerte perinatal del $2,6 \%$. Allotey y cols. (10), encontraron que los RN de madres con COVID-19 son más propensos a ser admitidos en la unidad de cuidados neonatales. Es muy probable que la asociación de la enfermedad con la prematuridad explique estos hallazgos, toda vez que la tasa de prematuridad en este estudio fue del $40 \%$.

Una de las preocupaciones con relación a la embarazada con COVID-19 tiene que ver con el riesgo de transmisión de la enfermedad al recién nacido. Mucho se ha dicho sobre la transmisión vertical, aspecto que se ha ido modificando con el tiempo. En la literatura se encuentran estudios no concluyentes (21), otros que reportan un riesgo mínimo $(8,13,14,42)$ y otros que demuestran la transmisión vertical (15). La SOGV ha señalado que la transmisión vertical es incierta, no se ha demostrado evidencia de la misma, incluso en estudios publicados de recién nacidos de madres infectadas no se demostró presencia del virus en muestras de líquido amniótico, placenta o sangre de cordón, y ha recomendado que a todos los recién nacidos se les debe tomar la muestra para descarte de infección viral en el periodo neonatal inmediato (33). Carvajal y cols. (34) también describen la necesidad de realizar la prueba de PCR-RT para SARS-CoV-2 en los neonatos asintomáticos, en las primeras 24 horas de nacido, y si presenta síntomas, tomarla inmediatamente. En esta serie, los 10 recién nacidos tuvieron su prueba de PCR-RT negativa para SARSCoV-2.

Se concluye que la COVID-19 se asocia a evolución materna y perinatal adversa. La frecuencia de la enfermedad en el Hospital Central de San Cristóbal, entre agosto 2020 y julio 2021 fue del $0,5 \%$. La enfermedad fue leve en el $53 \%$ de los casos, moderada en el $16,7 \%$ y grave en el $30 \%$. No se encontraron factores de riesgo para evolución grave de la COVID-19. Hubo complicaciones obstétricas en el $90 \%$ de las pacientes y la frecuencia de muerte materna fue del 20,0 \%. La evolución de la COVID-19 no se asoció a la presencia de patologías propias ni asociadas a la gestación. La tasa de cesárea fue de 86,7 \%. La evolución perinatal fue satisfactoria en 21 pacientes. La frecuencia de muerte perinatal fue del $23,3 \%$.

Se recomienda que, dado que 1 de cada 200 gestantes que ingresan a la institución, tiene diagnóstico de COVID-19, es necesario incorporar nuevos protocolos para la evaluación y pesquisa de la enfermedad, así como la detección de sus factores de riesgo, incluyendo la realización de la PCR-RT de rutina a todas las embarazadas, como método más objetivo que el examen clínico, para el diagnóstico. Además, aprovechar la ventana de oportunidad que brinda el control prenatal para educar a las gestantes sobre prevención, incluyendo medidas de bioseguridad y vacunación.

En vista de la elevada frecuencia de complicaciones obstétricas y perinatales, entre ellas, la prematuridad, insistir en el manejo multidisciplinario de las gestantes, entre el servicio de medicina maternofetal, neonatología, medicina interna e infectología.

Se sugiere revisar las razones que justifican la elevada tasa de cesáreas e incorporar a la COVID-19 como una de las principales causas de muerte materna y perinatal. 
Finalmente, es muy importante mantener la investigación continua con relación a la enfermedad, ya que es una enfermedad nueva con un gran impacto negativo sobre la evolución materna y perinatal.

\section{Sin conflictos de interés.}

\section{REFERENCIAS}

1. Federación Latinoamericana de Asociaciones de Medicina Perinatal (FLAMP), Federación Latinoamericana de Sociedades de Obstetricia y Ginecología (FLASOG). COVID-19. 1era Edición. Guayaquil: Editorial Ecuasalud. 2020.

2. Acuña D, Arias L, Collazo N, Cuevas G, Estrella M, Tapia D, et al. Infección por COVID-19 en Ginecología y Obstetricia. 1era Edición. Pérez M, Hernández M, editores. Ciudad de México: Edición y Farmacia, SA de CV; 2020.

3. Lu R, Zhao X, Li J, Niu P, Yang B, Wu H, Wang W, et al. Genomic characterisation and epidemiology of 2019 novel coronavirus: implications for virus origins and receptor binding. Lancet. 2020; 395(10224):565574. doi: 10.1016/S0140-6736(20)30251-8.

4. Organización Mundial de la Salud [Internet]. Ciudad: Brote de enfermedad por coronavirus (COVID-19); 2020 [actualizado 05 de marzo de 2020; consultado 15 de febrero de 2021]. Disponible en: https://www.who. int/es/emergencies/diseases/novel-coronavirus2019

5. Calvo C, García López-Hortelano M, de Carlos Vicente JC, Vázquez Martínez JL; Grupo de trabajo de la Asociación Española de Pediatría para el brote de infección por Coronavirus. [Recommendations on the clinical management of the COVID-19 infection by the «new coronavirus» SARS-CoV2. Spanish Paediatric Association working group]. An Pediatr (Barc). 2020; 92(4):241.e1-241.e11. Spanish. doi: 10.1016/j. anpedi.2020.02.001.

6. American College of Obstetrician and Gynecología; Society for Maternal Fetal Medicine [Internet]. New York: Evaluación y manejo ambulatorio para las gestantes con sospecha o confirmación del nuevo coronavirus (COVID-19); 2020 [actualizado 30 de abril 2020; consultado 18 de febrero de 2021]. Disponible en: http://www.scielo.org.pe/pdf/rgo/v66n2/23045132-rgo-66-02-00016.pdf

7. Vigil-De Gracia P, Luo C. Coronavirus infection
(SARS-CoV-2) in pregnant women: Systematic review. Authorea.2020.doi: 10.22541/au.158592515.56139684

8. Pettirosso E, Giles M, Cole S, Rees M. COVID-19 and pregnancy: A review of clinical characteristics, obstetric outcomes and vertical transmission. Aust N Z J Obstet Gynaecol. 2020; 60(5):640-659. doi: 10.1111/ ajo. 13204.

9. American College of Obstetrician and Gynecología [Internet]. New York: Novel Coronavirus 2019 (COVID-19); 2020 [actualizado 14 de diciembre de 2020; consultado 12 de enero de 2021]. Disponible en: $\quad$ https://www.acog.org/clinical/clinicalguidance/practice-advisory/articles/2020/03/novelcoronavirus-2019

10. Allotey J, Stallings E, Bonet M, Yap M, Chatterjee S, Kew $\mathrm{T}$, et al. Clinical manifestations, risk factors, and maternal and perinatal outcomes of coronavirus disease 2019 in pregnancy: living systematic review and metaanalysis. BMJ. 2020; 370:m3320. doi: 10.1136/bmj. m3320.

11. Akhtar H, Patel C, Abuelgasim E, Harky A. COVID-19 (SARS-CoV-2) Infection in Pregnancy: A Systematic Review. Gynecol Obstet Invest. 2020; 85(4):295-306. doi: 10.1159/000509290.

12. Simões E Silva AC, Leal CRV. Is SARS-CoV-2 Vertically Transmitted? Front Pediatr. 2020; 8:276. doi: 10.3389/fped.2020.00276.

13. Deprest J, Choolani M, Chervenak F, Farmer D, Lagrou K, Lopriore E, et al. Fetal Diagnosis and Therapy during the COVID-19 Pandemic: Guidance on Behalf of the International Fetal Medicine and Surgery Society. Fetal Diagn Ther. 2020; 47(9):689-698. doi: 10.1159/000508254.

14. Melo GC, Araújo KCGM. COVID-19 infection in pregnant women, preterm delivery, birth weight, and vertical transmission: a systematic review and metaanalysis. Cad Saude Publica. 2020; 36(7):e00087320. doi: 10.1590/0102-311x00087320.

15. Vivanti AJ, Vauloup-Fellous C, Prevot S, Zupan V, Suffee C, Do Cao J, et al. Transplacental transmission of SARS-CoV-2 infection. Nat Commun. 2020; 11(1):3572. doi: 10.1038/s41467-020-17436-6.

16. Dashraath P, Wong JLJ, Lim MXK, Lim LM, Li S, Biswas A, Choolani $\mathrm{M}$, et al. Coronavirus disease 2019 (COVID-19) pandemic and pregnancy. Am J Obstet Gynecol. 2020; 222(6):521-531. doi: 10.1016/j. ajog.2020.03.021. 
17. Di Mascio D, Khalil A, Saccone G, Rizzo G, Buca D, Liberati $\mathrm{M}$, et al. Outcome of coronavirus spectrum infections (SARS, MERS, COVID-19) during pregnancy: a systematic review and meta-analysis. Am J Obstet Gynecol MFM. 2020; 2(2):100107. doi: 10.1016/j.ajogmf.2020.100107.

18. Huang C, Wang Y, Li X, Ren L, Zhao J, Hu Y, et al. Clinical features of patients infected with 2019 novel coronavirus in Wuhan, China. Lancet. 2020; 395(10223):497-506. doi: 10.1016/S01406736(20)30183-5.

19. Castejón O, Canache L, Lara A, Veroes J. Infection by coronavirus in the placental villi. Rev Electron Biomed [Internet]. 2019 [consultado noviembre de 2020]; 3: [aprox. 4 páginas]. Disponible en: https://biomed. uninet.edu/2019/n3/castejon.html

20. Dávila-Aliaga C, Espínola-Sánchez M, MendozaIbáñez E, Guevara-Ríos E, Torres-Marcos E, HinojosaPérez R, et al. [Perinatal outcomes and serological results in neonates of pregnant women seropositive to SARS-CoV-2: A cross-sectional descriptive study]. Medwave. 2020; 20(11):e8084. Spanish. doi: 10.5867/ medwave.2020.11.8084.

21. Caparros-González RA. [Maternal and neonatal consequences of coronavirus COVID-19 infection during pregnancy: a scoping review]. Rev Esp Salud Pública. 2020; 94:e202004033. Spanish. DOI: 10.4321/ S1135-57272020000100025

22. Tyrrell DA, Bynoe ML. Cultivation of a novel type of common-cold virus in organ cultures. Br Med J. 1965; 1(5448):1467-1470. doi: 10.1136/bmj.1.5448.1467.

23. Enjuanes L, Smerdou C, Castilla J, Antón IM, Torres JM, Sola I, et al. Development of protection against coronavirus induced diseases. A review. Adv Exp Med Biol. 1995; 380:197-211. doi: 10.1007/978-1-46151899-0 34.

24. Lan J, Ge J, Yu J, Shan S, Zhou H, Fan S, et al. Structure of the SARS-CoV-2 spike receptor-binding domain bound to the ACE2 receptor. Nature. 2020; 581(7807):215-220. doi: 10.1038/s41586-020-2180-5.

25. Hoffmann M, Kleine-Weber H, Schroeder S, Krüger N, Herrler T, Erichsen S, et al. SARS-CoV-2 Cell Entry Depends on ACE2 and TMPRSS2 and Is Blocked by a Clinically Proven Protease Inhibitor. Cell. 2020; 181(2):271-280.e8. doi: 10.1016/j.cell.2020.02.052.

26. Lin L, Lu L, Cao W, Li T. Hypothesis for potential pathogenesis of SARS-CoV-2 infection-a review of immune changes in patients with viral pneumonia.
Emerg Microbes Infect. 2020; 9(1):727-732. doi: 10.1080/22221751.2020.1746199.

27. López M, Goncé A, Meler E, Hernández S, Cobo T, Guirado L, et al. Protocolo: coronavirus (COVID-19) y gestación [Internet]. Barcelona: Centro de Medicina Fetal y Neonatal de Barcelona y Clínic Hospital Universitario de Barcelona; [actualizado 8 de marzo de 2021; consultado 20 de marzo de 2021]. Disponible en: https://medicinafetalbarcelona.org/protocolos/es/ patologia-materna-obstetrica/covid19-embarazo.html

28. Herrera M, Arenas J, Rebolledo M, Barón J, de León $\mathrm{J}$, Yomayuza N, et al. Guía de la FIMMF para la embarazada con infección por coronavirus [Internet]. Bogotá: Fundación Internacional de Medicina Materno Fetal; 2020 [actualizado abril 2020; consultado noviembre 2020]. Disponible en: https://www.flasog. org/static/COVID-19/FIMMF.pdf

29. To KK, Tsang OT, Leung WS, Tam AR, Wu TC, Lung $\mathrm{DC}$, et al. Temporal profiles of viral load in posterior oropharyngeal saliva samples and serum antibody responses during infection by SARS-CoV-2: an observational cohort study. Lancet Infect Dis. 2020; 20(5):565-574. doi: 10.1016/S1473-3099(20)30196-1.

30. Kimberlin DW, Stagno S. Can SARS-CoV-2 Infection Be Acquired In Utero?: More Definitive Evidence Is Needed. JAMA. 2020; 323(18):1788-1789. doi: 10.1001/jama.2020.4868.

31. World Health Organization [Internet]. Ginebra: Coronavirus disease 2019 (COVID-19). Situation report - 73; 2020 [consultado noviembre 2020]. Disponible en: https://apps.who.int/iris/handle/10665/331686

32. Zhang XY, Huang HJ, Zhuang DL, Nasser MI, Yang $\mathrm{MH}$, Zhu $\mathrm{P}$, et al. Biological, clinical and epidemiological features of COVID-19, SARS and MERS and AutoDock simulation of ACE2. Infect Dis Poverty. 2020; 9(1):99. doi: 10.1186/s40249-02000691-6.

33. Pérez Wulf JA, Márquez D, Lugo C, Veroes J, Cortés R, Di Muro J, et al. Embarazada y Covid-19. Guía provisional. Sociedad de Obstetricia y Ginecología de Venezuela. Rev Obstet Ginecol Venez [Internet]. 2020 [consultado 28 de julio de 2021]; 80(Sup 1):S3-S29. Disponible en: http://www.sogvzla. org.ve/sogvzla20186/cms/svcobtenerpdfrevista. php?id=0000000098\&tipo $=$ normal\&fila $=3$

34. Carvajal A, Romero M; Red COVID y Gestación. Manual de bolsillo para el tratamiento de las embarazadas propuesto por la "Red Covid-19 y 
Gestación". Rev Obstet Ginecol Venez [Internet]. 2020 [consultado 28 de julio de 2021]; 80(Sup 1):S45-S49. Disponible en: http://www.sogvzla. org.ve/sogvzla $20186 / \mathrm{cms} / \mathrm{svcobtenerpdfrevista.}$ php?id $=0000000098 \&$ tipo $=$ normal \&fila $=6$

35. Carvajal A. Márquez D. Nuevo Coronavirus (SarsCov-2) y embarazo. Rev Obstet Ginecol Venez [Internet]. 2020 [consultado 28 de julio de 2021]; 80(1):53-63. Disponible en: http://www.sogvzla. org.ve/sogvzla $20186 / \mathrm{cms} / \mathrm{svcobtenerpdfrevista.}$ php?id $=0000000097 \&$ tipo $=$ normal\&fila $=9$

36. González Romero D, Ocampo Pérez J, González Bautista L, Santana-Cabrera L. Pregnancy and perinatal outcome of a woman with COVID-19 infection. Rev Clin Esp (Barc). 2020; 220(8):533-534. doi: 10.1016/j. rceng.2020.04.005.

37. Dubey P, Reddy SY, Manuel S, Dwivedi AK. Maternal and neonatal characteristics and outcomes among COVID-19 infected women: An updated systematic review and meta-analysis. Eur J Obstet Gynecol Reprod Biol. 2020; 252:490-501. doi: 10.1016/j. ejogrb.2020.07.034.

38. Parto prematuro. En: Cunningham FG, Leveno KJ, Bloom SL, Hauth JC, Rouse DJ, Spong CY. Williams Obstetricia. 23a edición. México DF: Mc Graw Hill; 2011. Pp 804-831.
39. OPS/OMS [Internet]. Washington DC: Alerta Epidemiológica: COVID-19 durante el embarazo13 de agosto de 2020 [consultado 20 de noviembre de 2020]. Disponible en: https://www.paho.org/es/ documentos/alerta-epidemiologica-covid-19-duranteembarazo-13-agosto-2020

40. Organización Mundial de la Salud [Internet]. Ginebra: Declaración de la OMS sobre tasas de cesárea. Resumen ejecutivo; abril 2015 [consultado diciembre 2016]. Disponible en: https://www.who.int/ reproductivehealth/publications/maternal_perinatal_ health/cs-statement/es/

41. World Health Organization [Internet]. Ginebra: COVID-19 clinical management: living guidance, 2021 [actualizado 25 de enero de 2021; consultado febrero de 2021]. Disponible en: https://apps.who.int/ iris/handle/10665/338882

42. Khalil A, Kalafat E, Benlioglu C, O’Brien P, Morris E, Draycott $\mathrm{T}$, et al. SARS-CoV-2 infection in pregnancy: A systematic review and meta-analysis of clinical features and pregnancy outcomes. E Clinical Medicine. 2020; 25:100446. doi: 10.1016/j.eclinm.2020.100446.

Recibido: 10 de diciembre de 2021 Aprobado: 15 de enero de 2022 